\title{
Role of the Nucleoid-Associated Protein H-NS in the Synthesis of Virulence Factors in the Phytopathogenic Bacterium Erwinia chrysanthemi
}

\author{
William Nasser, ${ }^{1}$ Michel Faelen, ${ }^{2}$ Nicole Hugouvieux-Cotte-Pattat, ${ }^{1}$ and Sylvie Reverchon ${ }^{1}$ \\ ${ }^{1}$ Unité de Microbiologie et Génétique, ERS-CNRS 2009, INSA, Bat 406, 20, Av. A. Einstein, F-69621 \\ Villeurbanne Cedex, France; ' 2 aboratoire de Génétique, Université Libre de Bruxelles, rue des Chevaux, \\ 67 B-1640 Rhode St Genèse, Belgique. \\ Accepted 19 September 2000.
}

\begin{abstract}
The ability of the enterobacterium Erwinia chrysanthemi to induce pathogenesis in plant tissue is strongly related to the massive production of plant-cell-wall-degrading enzymes (pectinases, cellulases, and proteases). Additional factors, including flagellar proteins and exopolysaccharides (EPS), also are required for the efficient colonization of plants. Production of these virulence factors, particularly pectate lyases, the main virulence determinant, is tightly regulated by environmental conditions. The possible involvement of the protein $\mathrm{H}-\mathrm{NS}$ in this process was investigated. The E. chrysanthemi hns gene was cloned by complementation of an Escherichia coli hns mutation. Its nucleotide sequence contains a 405-bp open reading frame that codes for a protein with $85 \%$ identity to the $E$. coli $\mathrm{H}$ NS protein. An E. chrysanthemi hns mutant was constructed by reverse genetics. This mutant displays a reduced growth rate and motility but an increased EPS synthesis and sensitivity toward high osmolarity. Furthermore, pectate lyase production is dramatically reduced in this mutant. The hns mutation acts on at least two conditions affecting pectate lyase synthesis: induction of pectate lyase synthesis at low temperatures $\left(25^{\circ} \mathrm{C}\right)$ is no longer observed in the hns mutant and induction of pectate lyase production occurs in the late stationary growth phase in the hns background, instead of in the late exponential growth phase as it does in the parental strain. Moreover, the $E$. chrysanthemi hns mutant displays reduced virulence on plants. Taken together, these data suggest that H-NS plays a crucial role in the expression of the virulence genes and in the pathogenicity of $E$. chrysanthemi.
\end{abstract}

Additional keyword: regulation.

H-NS is a small DNA-binding protein that belongs to the class of nucleoid-associated proteins of enterobacteria. This protein is involved in the regulation, primarily at the transcriptional level, of a variety of unrelated genes in Es-

Corresponding author: W. Nasser; current address: Institut für Genetik und Mikrobiologie, LMU, A/G Kahmann, Maria-Ward-Str. 1a, 80638 München, Germany; Telephone: +49 $8921 \quad 80 \quad 61 \quad 97$; E-mail: w.nasser@1rz.uni-muenchen.de cherichia coli and Salmonella typhimurium (Atlung and Ingmer 1997; Ussery et al. 1994) and acts as a modulator of virulence-associated gene expression in the human enteropathogenic Shigella (Maurelli and Sansonetti 1988), Salmonella (Harrison et al. 1994), and enteroinvasive E. coli strains (Colonna et al. 1995). Most of the H-NS target genes are regulated by environmental signals such as osmolarity, temperature, growth phase, and $\mathrm{pH}$ (Atlung and Ingmer 1997). Several investigations, mostly performed in E. coli and $S$. typhimurium, have shown that the hns gene is autoregulated (Falconi et al. 1993; Ueguchi et al. 1993) and its nucleoidassociated expression increases several-fold following cold shock (LaTeana et al. 1991).

The gene encoding H-NS or structurally and functionally related proteins has been identified in other gram-negative bacteria such as Haemophilus influenzae (Dorman et al. 1999; Fleischmann et al. 1995; Hinton et al. 1992;), Bordetella pertussis (Goyard and Bertin 1997), Vibrio cholerae, and Rhodobacter capsulatus (Bertin et al. 1999). Moreover, a gene with C-terminal homology to H-NS has been found in the plant pathogen Xanthomonas oryzae (EMBL X97866) (Dorman et al. 1999). In these bacteria, the H-NS function remains unclear, mostly because of the difficulty of obtaining mutants with an inactivated $h n s$-like gene. As a result of indirect studies (e.g., complementation of various E. coli $\mathrm{H}-\mathrm{NS}$-associated phenotypes and in vitro band-shift assays), it has been suggested that these proteins display transcriptional regulatory functions similar to the E. coli H-NS (Bertin et al. 1999). Concerning plant pathogenic bacteria, in the absence of any relevant investigation, the role of H-NS remains unclear, particularly in regard to its implication in the modulation of the expression of virulence genes.

The phytopathogenicity of the soft-rot enterobacteria of the genus Erwinia is mainly correlated with their ability to produce and secrete plant cell wall degrading enzymes (pectinases, cellulase, proteases). Among these extracellular enzymes, pectate lyases (Pel) play a predominant role in plant tissue maceration (Collmer and Keen 1986; HugouvieuxCotte-Pattat et al. 1996). Nevertheless, plant colonization by pectinolytic Erwinia is a multifactorial process, requiring numerous secondary factors such as exopolysaccharides (EPS) (Condemine et al. 1999), lipopolysaccharide (LPS) (Schoonejans et al. 1987), iron assimilation (Enard et al. 
1988), the Hrp system (Bauer et al. 1994), motility (Mulholland et al. 1994), and proteins involved in resistance against plant defense mechanisms (El Hassouni et al. 1999; Lopez-Solanilla et al. 1998).

In Erwinia spp., production of pectate lyases, the main virulence determinant, is tightly regulated and responds to various physiological controls, including growth phasedependent induction, catabolic repression, and variations in environmental conditions such as the presence of pectin and plant extracts, iron starvation, temperature, or high osmolarity (Hugouvieux-Cotte-Pattat et al. 1996). Previous studies allowed the identification of several regulators (KdgR, PecS, PecT, Fur, ExpI-ExpR, Pir, and CRP) that modulate the synthesis of pectate lyases (Franza et al. 1999; Nasser et al. 1998; Nomura et al. 1998; Praillet et al. 1996; Reverchon et al. 1991; Reverchon et al. 1994; Reverchon et al. 1997; Surgey et al. 1996). KdgR, PecS, PecT, and Fur are repressors, whereas CRP, Pir, and ExpR mainly act as activators on pel expression. Most of these systems are not limited to the control of pectate lyase production but also affect other factors that are, or could be, involved in virulence such as protein secretion, motility, pigment, cellulase and protease production, EPS synthesis, and iron capture. Signals transduced by these regulators are diverse and not always identified. Induction of pel gene expression by KDG, an inducer derived from pectin catabolism, is mediated by $\mathrm{KdgR}$ (Nasser et al. 1994; Reverchon et al. 1991). Among environmental factors affecting the synthesis of pectate lyase, plant signals other than KDG are important. The chemical nature of the additional inducing factor(s) present in plant extracts, however, is not yet known. Preliminary characterization of one inducing factor from carrot root suggested that it could be an oligosaccharide (Bourson et al. 1993). This plant factor induces the expression of pectinase genes only in synergy with pectic compounds, and the induction by plant extracts is mediated by the Pir activator (Nomura et al. 1998). Induction of pectate lyase production by iron starvation is mediated by Fur, which also controls chrysobactin- and achromobactin-dependent iron transport systems (Franza et al. 1999). Catabolite repression is mediated by the cyclic AMP (cAMp) receptor protein-cAMP complex, which is the main activator of pel genes represses EPS production (Condemine et al. 1999; Nasser et al. 1997; Reverchon et al. 1997). ExpR is a quorum-sensing regulator that modulates pel gene expression in response to $\mathrm{N}$-acyl-homoserine lactones generated by the ExpI synthase (Nasser et al. 1998; Reverchon et al. 1998). Finally, the signals to which the PecS and PecT regulators respond are not yet known. In addition to the pel genes, PecS controls cellulase, protease, and indigoidine production (Reverchon et al. 1994), whereas PecT modulates motility and EPS synthesis (Castillo and Reverchon 1997; Condemine et al. 1999). Despite the identification of numerous regulatory proteins, the mechanisms responsible for regulation of Erwinia spp. virulence genes by various critical environmental factors such as osmolarity, temperature, or growth phase remain unclear.

To gain further insight into the regulation of virulence gene expression in E. chrysanthemi, we looked for the role of the nucleoid-associated protein H-NS in this process. Here we report the cloning of the E. chrysanthemi hns gene and the characterization of the corresponding mutant. Interestingly, this mutant displays reduced pectate lyase activity and an attenuated pathogenicity.

\section{RESULTS}

\section{Cloning and sequencing}

of the E. chrysanthemi hns homolog.

In $E$. coli, mutations in the hns gene abolish motility but confer the ability to catabolize salicin (Bertin et al. 1999; Defez and De Felice 1981). The E. chrysanthemi hns gene was cloned by analysis of salicin catabolism in an E. coli hns mutant (TP504Ahns) transformed with an E. chrysanthemi gene library constructed in pBR322. Out of 5,000 transformants, three plasmids were isolated because they deprived the corresponding clones of the ability to catabolize salicin. They also were able to restore swarming of the hns mutant. We first focused on one of these plasmids, pWN3094, which contained a 4.2-kb insert (Fig. 1). Subcloning revealed that the smallest subclone conferring complementation of the hns defects contained a 1.1-kb ClaI-HindIII fragment (Fig. 1). This fragment, used as a probe in hybridization experiments, showed that the two other selected plasmids contain the same DNA fragment. Identification of a single 6.6-kb SalI hybridizing fragment in the chromosomal DNA of E. chrysanthemi indicated that a single copy of the corresponding gene is present in the 3937 genome (data not shown).

The nucleotide sequence of the 1.1-kb ClaI-HindIII fragment containing the E. chrysanthemi hns gene was determined (GenBank accession no. X89444). An open reading frame (ORF) of $405 \mathrm{bp}$, extending from position 217 to 621 and showing similarity to the E. coli hns gene, was identified. The ATG codon is preceded by a putative Shine-Dalgarno sequence, GAGA. Computer analysis indicated that the presence of a putative $\sigma^{70}$-type promoter -35 (TTGCAG) and -10 (TATTAT) were located 42- and 59-bp upstream from the translation start codon, respectively. At the $3^{\prime}$ end of the hns gene, an inverted repeat may form a 18-bp hairpin that could act as a rho-independent transcription terminator. Moreover, downstream of the hns gene and convergently transcribed, the $3^{\prime}$ end of a partial ORF corresponding to the galU gene was detected. By contrast, this complex gene is transcribed in the opposite direction of $h n s$, in accordance with the organization in E. coli and S. typhimurium.

The H-NS ORF encodes a 135 amino acid (aa) protein exhibiting high relatedness with H-NS proteins from Serratia marcescens (91\% aa identity), E. coli and Salmonella typhimurium (85\%), Shigella flexneri (83\%), Proteus vulgaris $(80 \%)$, and Haemophilus influenzae (48\%) (Atlung and Ingmer 1997), with StpA proteins from E. coli $(58 \%)$ and S. typhimurium (54\%) (Zhang and Belfort 1992) and the Vich protein from Vibrio cholerae (55\%). A multiple sequence alignment of H-NS bacterial homologs, including the E. chrysanthemi protein, performed by Dorman et al. (1999) revealed a high conservation within the three functional domains (oligomerization, linker, and nucleic acid binding domains).

\section{Construction and phenotypes of an E. chrysanthemi hns mutant.}

To study the function of H-NS in E. chrysanthemi, the hns gene was inactivated by insertion of a kanamycin resistance $\left(\mathrm{Kan}^{\mathrm{r}}\right)$ cartridge into the unique $A f l I I$ site located at the beginning of the coding region. Attempts to recombine this hns::Kan insertion into the E. chrysanthemi chromosome were 
unsuccessful. This difficulty was overcome by performing the homologous recombination in a merodiploid strain harboring the native hns gene on a low-copy number plasmid pRK767. After successful integration of the hns::Kan construct into the chromosome, the pRK-hns plasmid was eliminated by successive cultures without antibiotic, and mutants were analyzed by Southern blotting with the 1.1-kb HindIII-ClaI fragment of plasmid pWN3096 as the probe. We retained mutants in which the SalI hybridizing fragment was shifted from 6.6 to $8 \mathrm{~kb}$ as expected (data not shown).

The E. chrysanthemi hns mutant displays a mucoid phenotype on agar plates (suggesting an overproduction of EPS in this mutant), is nonmotile on semisolid medium (Fig. 2A), has a reduced growth rate (Fig. 3B), and is sensitive toward high osmolarity $(0.3 \mathrm{M} \mathrm{NaCl})$ (data not shown) compared with the wild-type strain. Such phenotypes are similar to those reported for E. coli and S. typhimurium hns mutants (Atlung and Ingmer 1997; Barth et al. 1995; Bertin et al. 1999; Hinton et al. 1992; Sledjeski and Gottesman 1995). In contrast with E. coli, wild-type $E$. chrysanthemi can already catabolize $\beta$-glucosides
(Barras et al. 1989). With regard to extracellular enzyme production, plate assays revealed that pectate lyase activity was reduced, whereas cellulase activity was increased in the hns mutant compared with the parental strain. All the phenotypes associated with the hns mutation were successfully complemented by the presence of pRK767-hns plasmid (data not shown), demonstrating that these phenotypes are specifically linked to H-NS.

The hns locus was localized on the E. chrysanthemi genetic map by chromosomal mobilization mediated by the plasmid pULB110. The hns::Kan ${ }^{\mathrm{r}}$ mutation appeared to be located between the markers trp- 1 and his- 1 with cotransfer frequencies of 62 and $8 \%$, respectively. This localization is similar to the hns position in the E. coli map. The hns mutation could be transduced with phage phiEC2 into various genetic backgrounds of E. chrysanthemi, although the transduction efficiency was very low in comparison with other markers (data not shown). As for the crp mutant, such reduced phiEC2 sensitivity is probably related to the overproduction of EPS that masks the LPS-receptor access to phiEC2 phages.

\section{Plasmids}

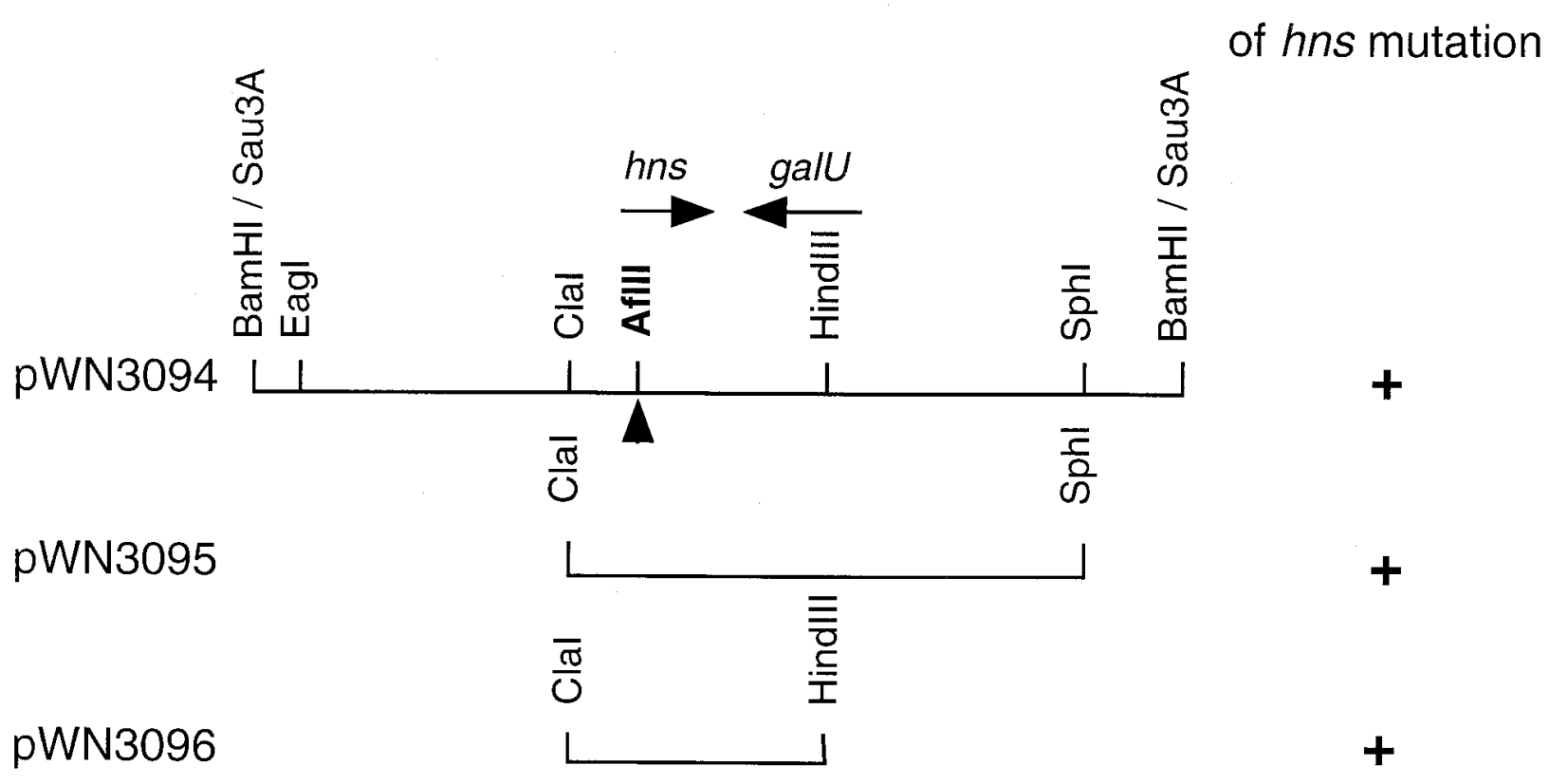

Fig. 1. Physical map of the 4.2-kb Sau3A DNA fragment containing the Erwinia chrysanthemi hns gene. Localization of the hns gene on plasmid pWN3094 was determined by complementation of the Escherichia coli hns mutant TP504 with the use of deletion derivatives such as pWN3095 and pWN3096. The $A f l I I$ insertion site of the $\operatorname{Kan}^{\mathrm{r}}$ cartridge is shown by an arrowhead. 


\section{Transcription of various genes}

\section{in the E. chrysanthemi hns mutant.}

In $E$. coli, one of the best studied systems whose transcription is strongly affected by H-NS is the osmotically controlled proU operon (proVWX) that encodes a transport system for the osmoprotectant glycine betaine (Dattananda and Gowrishankar 1989). To determine whether proU also is an H-NS target in E. chrysanthemi, we screened a genomic library by hybridization with the $E$. coli proX gene as probe. One selected plasmid, pSR2489, contains an 8.8-kb insert, including the proV-proW-proX-//ygaZ-ygaH-emrR-emrA genes, as established by partial sequencing of this insert. To monitor proU expression, we constructed a genetic fusion by introducing a $u i d A-\mathrm{Cm}^{\mathrm{r}}$ cassette into the unique MamI site localized inside proV. This proV::uidA fusion was then introduced by recombination into the $E$. chrysanthemi genome. Expression of the proV::uidA fusion was analyzed in wild-type and hns backgrounds (Fig. 2B). As observed in E. coli and S. typhimurium (Higgins et al. 1988), inactivation of the E. chrysanthemi hns gene results in a strong increase in proV expression demonstrating that proU also is an $\mathrm{H}-$ NS target in E. chrysanthemi. The extent of induction of proU activity by osmotic pressure was studied by measuring $\beta$ glucuronidase activity from proV::uidA operon fusion in the presence of $0.3 \mathrm{M} \mathrm{NaCl}$. In strain 3779, expression of the proV::uidA fusion increased approximately 50-fold in the highosmolarity medium (Fig. 2B). Supplementation of the highosmolarity medium with $1 \mathrm{mM}$ glycine betaine repressed proV::uidA expression to $25 \%$ of the salt-induced activity (Fig. 2B). Although strain A3779 lacks the ProU glycine betaine transport system, it can still utilize glycine betaine as an osmoprotectant, presumably through the low-affinity transport system OusA, which is homologous to the E. coli ProP system
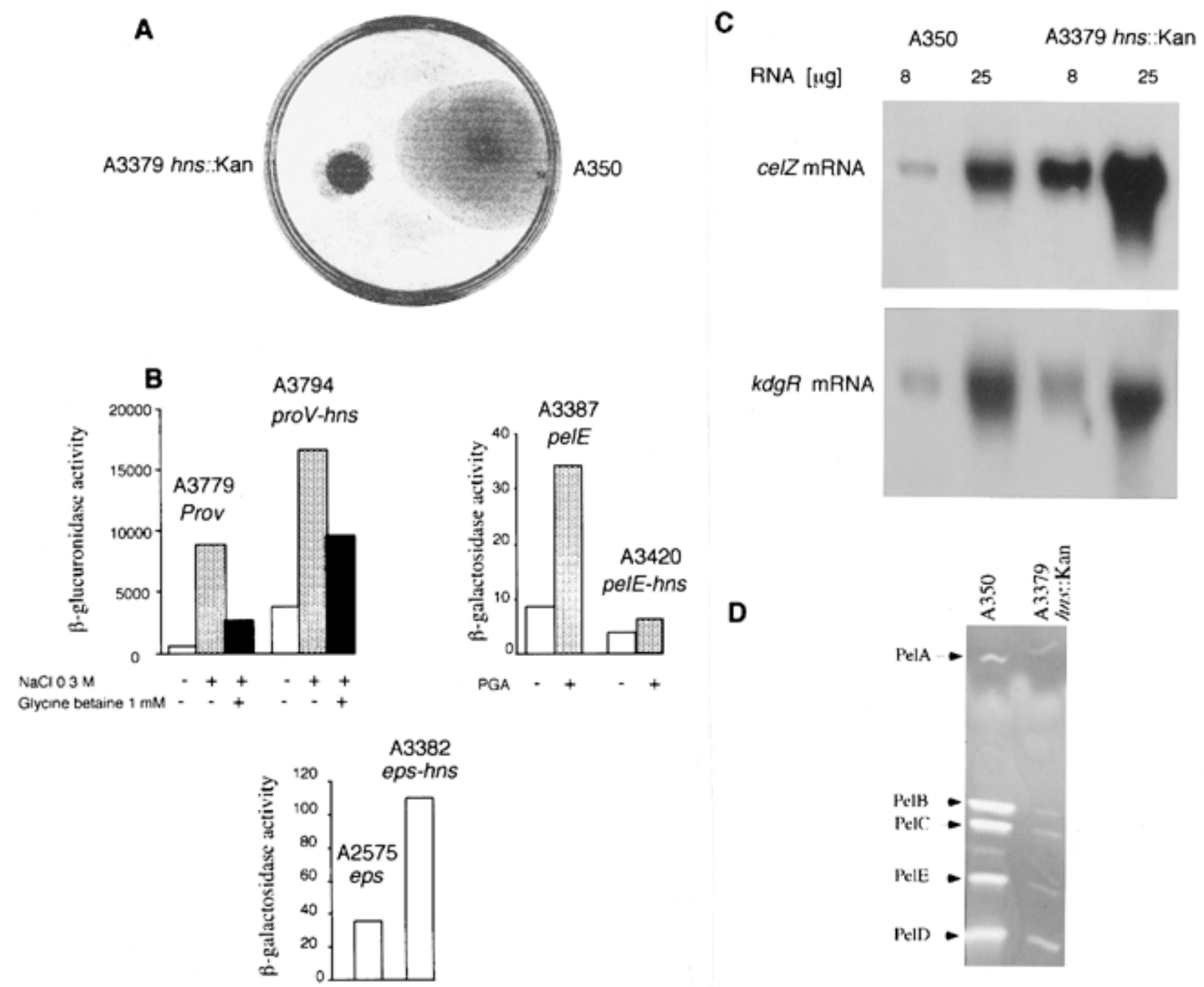

Fig. 2. Behavior of the Erwinia chrysanthemi hns mutant. A, Motility assay on semisolid medium. B, Expression of the chromosomal proV::uidA, pelE::lacZ, and eps::lacZ fusions in $\mathrm{H}_{-} \mathrm{NS}^{+}$and $\mathrm{H}_{-} \mathrm{NS}^{-}$strains. Open, gray and black bars = for proV::uidA, data obtained in minimal M63 medium twofold diluted with glycerol as carbon source in the absence and presence of $\mathrm{NaCl} 0.3 \mathrm{M}$ and in the presence of $\mathrm{NaCl} 0.3 \mathrm{M}$ and glycine betaine $1 \mathrm{mM}$, respectively; for pelE::lacZ, data obtained in minimal M63 medium with glycerol as carbon source in the absence and presence of polygalacturonate, respectively. Bacteria were grown at $30^{\circ} \mathrm{C}$ in minimal M63-glycerol medium, except for proV::uidA fusion strains, which were grown in twofold diluted M63-glycerol medium. Results are representative of three independent experiments. Standard deviations were less than $15 \%$. C, Representative examples of Northern blot analysis of celZ mRNA in $\mathrm{H}^{-N^{+}}{ }^{+}$and $\mathrm{H}_{-} \mathrm{NS}^{-}$strains. $k d g R$ RNA is shown as a control. D, Electrofocusing of pectate lyases produced by the E. chrysanthemi A350 (parental strain) and A3379 (hns::Kan). Strains were grown at $30^{\circ} \mathrm{C}$ in M63 glycerol minimal medium. Pectate lyase activity was revealed by the sandwich technique, as described (this paper). 
(Gouesbet et al. 1996). In the hns background, the basal transcription is strongly increased, but it is still inducible by high osmolarity. This pattern of proV expression in E. chrysanthemi is similar to that observed in E. coli and S. typhimurium (Barron et al. 1986; Lucht et al. 1994).

To determine whether the reduced pectate lyase production and the increased cellulase and EPS production observed in the hns background are caused by transcriptional control of $\mathrm{H}$ NS on these virulence factors, we analyzed expression of the eps operon and pelE and celZ genes with chromosomal gene fusions for eps and pelE genes and RNA analysis for the celZ gene. The celZ mRNA increased at least fivefold in the $\mathrm{H}_{-} \mathrm{NS}^{-}$ strain, whereas the $k d g R$ transcript was not noticeably affected by the hns inactivation (Fig. 2C). Furthermore, the eps expres-

A

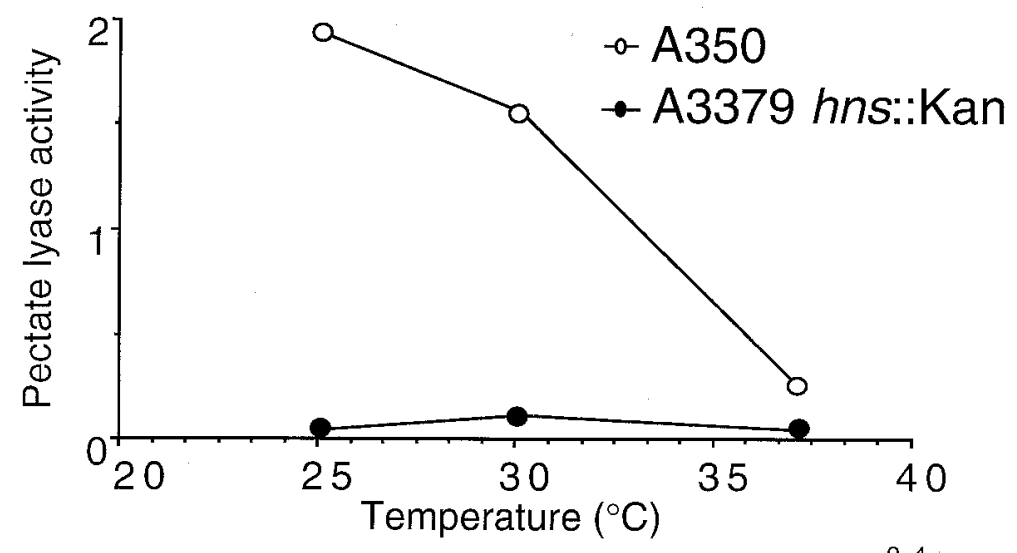

B
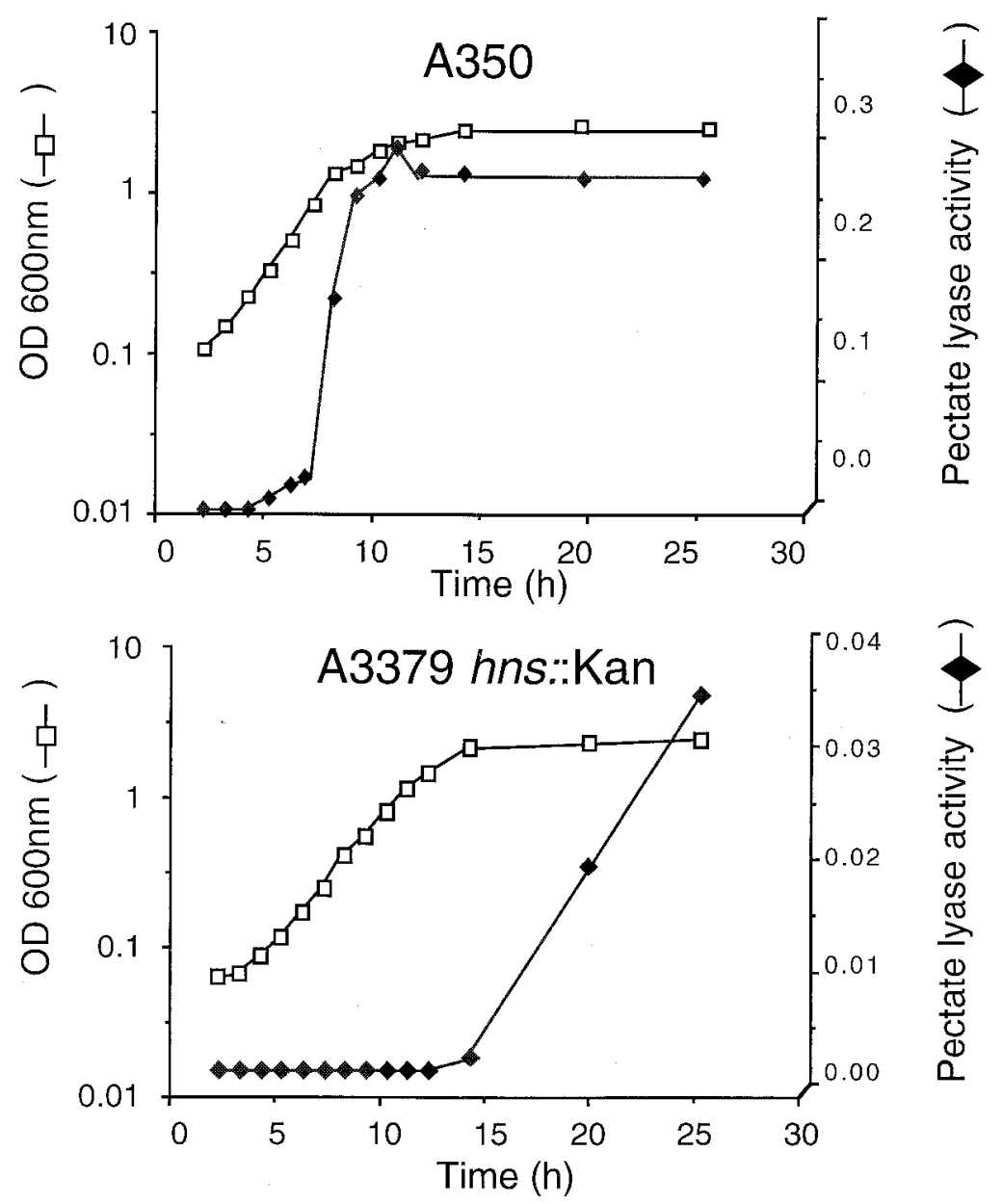

Fig. 3. Effect of hns mutation on the modulation of pectate lyase synthesis by temperature and growth phase. A, Bacteria were grown in minimal M63glycerol-polygalacturonate medium at various temperatures. Pectate lyase activities were assayed at the end of the exponential growth phase. B, Bacteria were grown in minimal M63-glycerol-polygalacturonate medium at $30^{\circ} \mathrm{C}$. Pectate lyase activity was monitored during $24 \mathrm{~h}$ of growth. White squares $=$ values of $\mathrm{OD}_{600 \mathrm{~nm}}$; black diamonds $=$ pectate lyase-specific activities. Results are representative of three independent experiments; standard deviations were less than $15 \%$. 
sion increased threefold in the hns mutant (Fig. 2B). In contrast, pelE expression decreased three- and sixfold in noninduced and induced conditions, respectively (Fig. 2B). These results confirm that $\mathrm{H}-\mathrm{NS}$ acts as a modulator of virulenceassociated gene expression in E. chrysanthemi.

\section{Pectate lyase production in the hns mutant.}

The E. chrysanthemi hns mutant was tested for pectate lyase production after growth under induced and noninduced conditions. In this genetic background, pectate lyase activity was reduced by 9 - and 22-fold in the absence and presence of polygalacturonate, respectively (data not shown). Zymogram analysis after isoelectrofocusing revealed that the synthesis of the five major pectate lyases (PelA, B, C, D, and E) is equally affected (Fig. 3D). Pectate lyase synthesis is regulated by many environmental conditions. We compared pectate lyase production in the wild-type strain and the hns mutant under conditions in which H-NS may play a role in E. coli, Salmonella, and Shigella (osmolarity, temperature, and growth phase) (Atlung and Ingmer 1997). Pectate lyase regulation by osmolarity was not affected in the hns mutant, indicating that $\mathrm{H}-\mathrm{NS}$ is not involved in this form of control (data not shown). In contrast, induction of pectate lyase synthesis at a low temperature $\left(25^{\circ} \mathrm{C}\right)$ was not observed in the hns mutant (Fig. 3A). Furthermore, in the hns background, induction of pectate lyase production occurs in the early stationary phase instead of in the late exponential growth phase as it did for the parental strain (Fig. 3B). Thus, H-NS seems to be involved in the modulation of the pectate lyase synthesis by temperature and growth phase.

\section{Plant tissue maceration and pathogenicity on Saintpaulia ionantha plants.}

The tissue-macerating ability of the hns mutant was compared with that of the wild-type strain 3937 by inoculation of chicory leaves. The macerating capacity of the hns mutant was strongly reduced in this plant organ (Fig. 4). Bacterial multiplication was monitored by estimation of the bacterial concentration in the rotted tissue 2 days after inoculation. The hns mutant displays at least a twofold reduced growth compared with the parental strain $\left(1.3\right.$ versus $2.1 \times 10^{10} \mathrm{CFU} / \mathrm{g}$ of rotted tissue, as calculated from values obtained in five independent experiments).

The pathogenic behavior of the hns mutant was compared with that of the parental strain 3937 after inoculation of potted $S$. ionantha plants. In all plants, inoculation of strain 3937 resulted in maceration of the whole leaf after 3 days. The rotting symptoms continued to spread throughout the petiole and, after 6 days, maceration expanding to a second petiole was detected in $25 \%$ of the infected plants. In contrast, the hns mutant failed to induce any symptoms in $17 \%$ of the plants, whereas in other plants it gave rise to a slow maceration that remained confined to the inoculated leaf (Fig. 4). Thus, the hns mutant was clearly less efficient than the wild-type strain in initiating maceration and inducing systemic soft-rot symptoms.

\section{DISCUSSION}

Virulence factor synthesis in E. chrysanthemi is regulated by various environmental conditions. Some of these signals (e.g., temperature, osmolarity, and growth phase) are mediated in E. coli and in related bacteria, Salmonella and Shigella, by the nucleoid-associated protein H-NS (Atlung and Ingmer 1997). Because in vivo random mutagenesis strategies in $E$. chrysanthemi were not effective in identifying the regulators responding to these environmental signals, we have initiated the cloning of the E. chrysanthemi hns gene to determine whether H-NS is involved in such control. The E. chrysanthemi H-NS protein shows a high identity, ranging from 85 to $91 \%$, with its E. coli, Salmonella, Shigella, and S. marcescens counterparts. The failure to clone this gene on a multicopy plasmid (Hulton et al. 1990), together with the difficulty in constructing an hns mutant and transducing the corresponding mutation, suggest that H-NS has an important role in the cell physiology of E. chrysanthemi, as established for its $E$. coli homologue (Atlung and Ingmer 1997). The E. chrysanthemi hns mutant displays most of the phenotypes associated with the E. coli hns mutation, e.g., loss of motility, reduction in growth rate, mucoidy, sensitivity toward high osmolarity, and overproduction of the osmoprotectant glycine betaine transport system. Synthesis of the E. chrysanthemi H-NS protein in $E$. coli leads to the complementation of all these phenotypes and vice versa. These results suggest that H-NS molecular regulatory mechanisms governing these pathways are globally conserved between these two enterobacteria.

Regulation of the E. chrysanthemi genes involved in pathogenesis was analyzed more carefully. Inactivation of the hns gene results in a strong increase in cellulase and EPS production. With RNA analysis and genetic fusion, we clearly established that the H-NS protein exerts its control at the transcriptional level, demonstrating that H-NS acts as a repressor of cellulase and EPS synthesis. In E. coli, H-NS negatively controls the EPS production in a cascade manner via repression of the specific RcsA activator synthesis (Sledjeski and Gottesman 1995). The mechanism in E. chrysanthemi could be similar, in view of the parallel control exerted by the environmental factors on the EPS synthesis in these two bacteria (Condemine et al. 1999; Gottesman 1995). H-NS is the third repressor of the EPS synthesis identified in E. chrysanthemi in addition to PecT and CRP. Preliminary investigations suggest that the action of H-NS and PecT is cumulative (W. Nasser, unpublished data). These data reveal the complexity of EPS synthesis in E. chrysanthemi. The multiplicity of these negative regulations might help bacteria to quickly adapt EPS synthesis to changes in environmental conditions. The presence of EPS is particularly important for the survival of bacteria in dry conditions. In addition to PecS, H-NS is the second repressor controlling celZ expression. It remains to be determined whether H-NS exerts its control on the celZ gene by a direct action or by a regulatory cascade.

In contrast, inactivation of the hns gene results in a strong decrease in pectate lyase production, suggesting an unusual activator function for H-NS. Only a few examples of positive regulation by H-NS have been reported in E. coli, and it is generally admitted that in these cases it results from indirect mechanisms (Atlung and Ingmer 1997). The observation that when pel genes are cloned in E. coli their expression is increased 2-fold in an E. coli hns mutant compared with the parental strain (James and Hugouvieux-Cotte-Pattat 1996) suggests that the positive control exerted by H-NS on pel gene expression results from an indirect mechanism in E. chrysanthemi, involving regulator(s) that is (are) absent in E. coli. 


\section{A}

A3380

hns::Kan

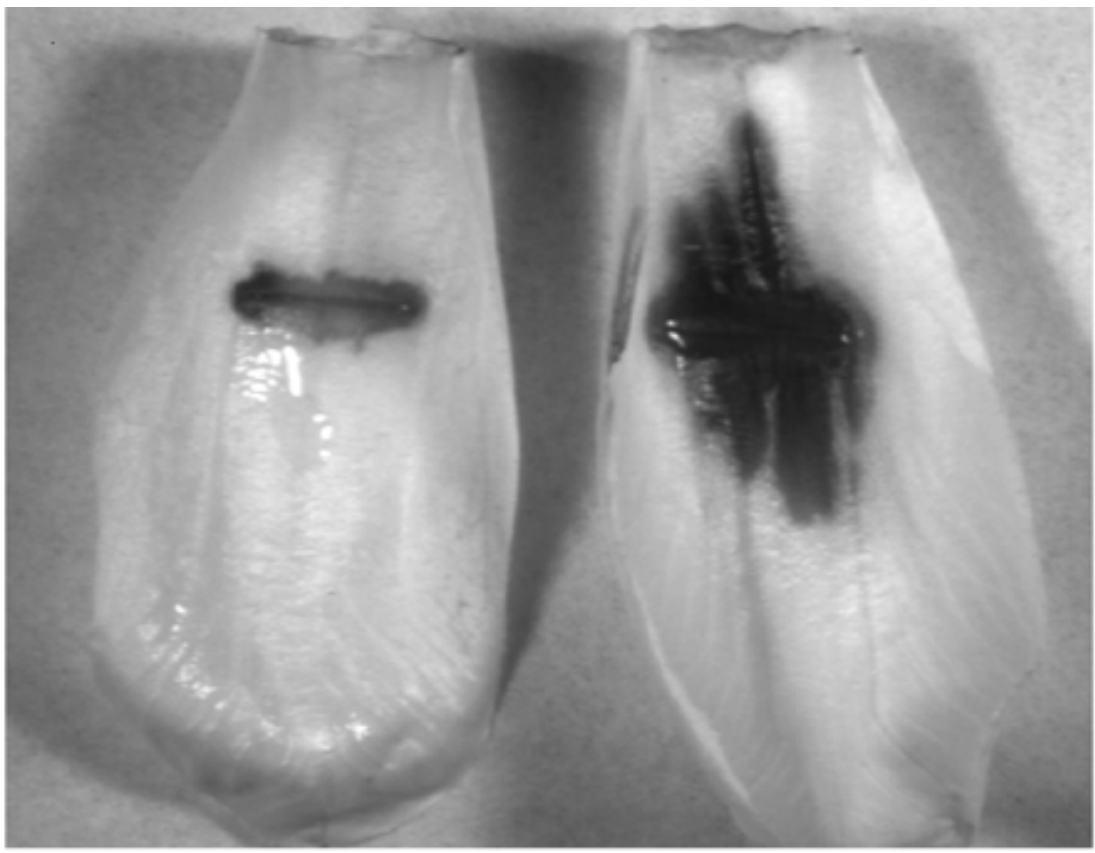

B

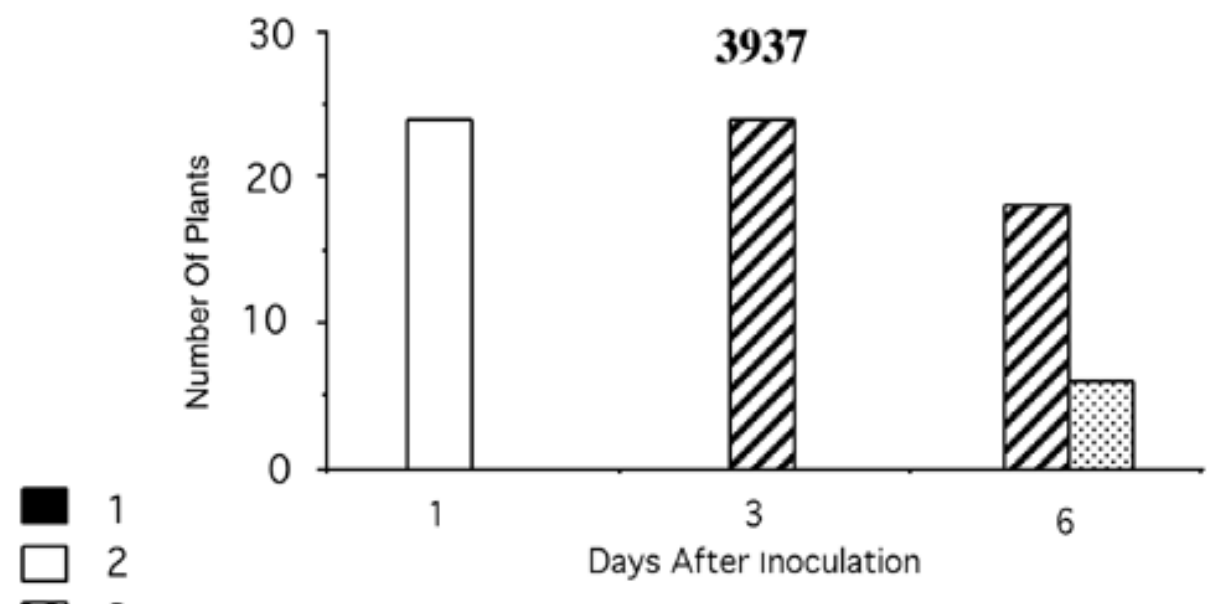

ש 3

ख 4

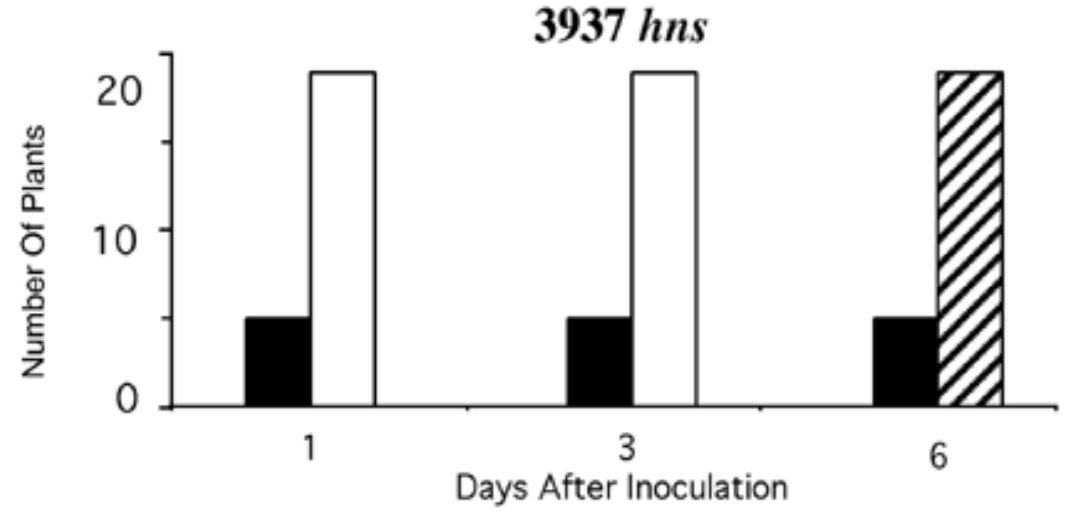

Fig. 4. Representative examples of symptoms induced by Erwinia chrysanthemi 3937 and its H-NS ${ }^{-}$derivative on A, chicory leaves and B, Saintpaulia ionantha. About $10^{7}$ cells were injected into chicory leaves, which were then incubated in a moist chamber at $30^{\circ} \mathrm{C}$ for $24 \mathrm{~h}$. Similar results were obtained on five different leaves. For $S$. ionantha infection, one leaf per plant was inoculated with $3 \times 10^{7}$ bacteria. Evolution of the pathogenesis was scored as follows: $1=$ no maceration symptom; $2=$ maceration localized at the inoculated area; $3=$ maceration covering the inoculated leaf; $4=$ maceration invading the petiole and other leaves. 
It is possible that the H-NS action on pectate lyase synthesis recruits a repressor such as $\mathrm{KdgR}$, PecS, PecT or is mediated via the RpoS-RsmA system. Indeed, recent data obtained in E. carotovora, a bacteria taxonomically related to $E$. chrysanthemi, indicate that RpoS activates the synthesis of the RsmA protein, which controls the expression of many genes, including pel genes (Mukherjee et al. 1998). In E . coli, H-NS controls RpoS synthesis (Atlung and Ingmer 1997). If these mechanisms are conserved in E. chrysanthemi, they could explain the effect of H-NS on pectate lyase synthesis. It is possible, however, that the H-NS action on pel gene expression may involve another regulator not yet identified. Further detailed work is required to determine the exact mechanism of $\mathrm{H}-\mathrm{NS}$ regulation on pel gene expression. Finally, H-NS is involved in the regulation of pectate lyase synthesis by temperature, as previously established for the virulence factors of S. typhimurium and S. flexneri (Atlung and Ingmer 1997). By regulating the pectate lyase synthesis in response to at least two signals rather than simply temperature or growth phase diminishes the likelihood that the pel genes will be expressed in inappropriate conditions.

In summary, we have shown that the global functions of the E. chrysanthemi H-NS protein are similar to those of H-NS in E. coli. Our data, however, reveal important novel features such as the degree of plant virulence is reduced in an H-NSdeficient strain. This reduced virulence probably results from the decreased pectate lyase levels, one of the most important virulence factors, but also could be a result of the motility loss and growth alteration of this strain. Further work will clarify the precise mechanisms by which H-NS controls the virulence genes expression, particularly those of pel genes, and should integrate this global regulator in the regulatory network controlling the synthesis of pectate lyases.

\section{MATERIALS AND METHODS}

\section{Bacterial strains, plasmids, and culture conditions.}

Bacterial strains and plasmids are described in Table 1. E. chrysanthemi and E. coli cells were grown at 30 and $37^{\circ} \mathrm{C}$, respectively, in Luria-Bertani (LB) medium or M63 minimal medium (Miller 1972) supplemented with carbon source $(0.2 \%$, except for polygalacturonate and pectin at $0.4 \%)$ and, when required, with $40 \mu \mathrm{g}$ of amino acids per milliliter and antibiotics at the following concentrations per milliliter: ampicillin, 25 or $100 \mu \mathrm{g}$; kanamycin and chloramphenicol, $50 \mu \mathrm{g}$; and tetracycline $20 \mu \mathrm{g}$. Fermentation tests were performed on MacConkey agar plates containing $0.2 \%$ salicin. To test motility, equal quantities of bacteria were loaded into holes in the middle of $0.4 \%$ LB agar plates. Plates were checked between 12 and $24 \mathrm{~h}$ after inoculation. Motility was determined by measuring the diameter of the colony.

\section{Genetic techniques.}

Transductions with phage phiEC2 were performed as described (Résibois et al. 1984). Marker exchange recombination

Table 1. Bacterial strains and plasmids

\begin{tabular}{|c|c|c|}
\hline Strain & Genotype or description & Source or reference \\
\hline \multicolumn{3}{|l|}{ Escherichia coli } \\
\hline NM522 & 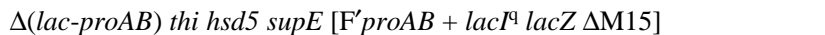 & Stratagene, La Jolla, CA, U.S.A. \\
\hline TP500 & F-leuB6 serB1203 thi-1 zch506::Tn10 zdd230::Tn9 & Lejeune and Danchin 1990 \\
\hline TP504 & F-leuB6 serB1203 thi-1 zch506::Tn10 zdd230::Tn9 $\Delta($ drc-drs-irk-hns $)$ & \\
\hline \multicolumn{3}{|c|}{ Erwinia chrysanthemi } \\
\hline 3937 & Wild-type strain isolated from Saintpaulia ionantha & Laboratory collection \\
\hline A350 & $\operatorname{lmrT}$ lacZ2 & Hugouvieux-Cotte-Pattat and Robert- Baudouy 1985 \\
\hline A3379 & $\operatorname{lmrT} T^{c}$ lacZ2 hns::Kan & This work \\
\hline A 3380 & hns::Kan & This work \\
\hline A2575 & $\operatorname{lmrT} T^{c}$ lacZ2 eps::Tn5-B21 & Condemine et al. 1999 \\
\hline A 3382 & lmrT $T^{c}$ lacZ2 eps::Tn5-B21 hns::Kan & This work \\
\hline A3387 & $\operatorname{lmr} T^{c}$ lacZ2 pelE::Mulac $\mathrm{Cm}$ & Laboratory collection \\
\hline A 3420 & lmrT lacZ2 pelE::Mulac $\mathrm{Cm}$ hns::Kan & This work \\
\hline A 3779 & $\operatorname{lmr} T^{c}$ lacZ2 proV::uidA $\mathrm{Cm}$ & This work \\
\hline A3794 & ImrT lacZ2 proV::uidA Cm hns::Kan & This work \\
\hline \multicolumn{3}{|c|}{ 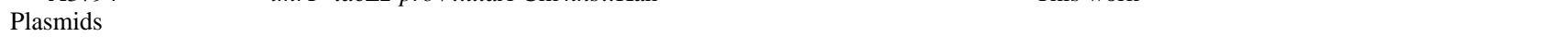 } \\
\hline pBR322 & $\mathrm{Ap}^{\mathrm{r}} \mathrm{Tc}^{\mathrm{r}}$ & Laboratory collection \\
\hline pSR1662 & $\begin{array}{l}\text { pBR322 with 2.4-kb NruI-PvuII fragment harboring the E. chrysan- } \\
\text { themi celZ gene }\end{array}$ & Laboratory collection \\
\hline pWN2144 & $\begin{array}{l}\text { pBS with } 1.3-\mathrm{kb} P v u \mathrm{I}-\text { Sna } \mathrm{BI} \text { fragment harboring the E. chrysanthemi } \\
k d g R \text { gene }\end{array}$ & Laboratory collection \\
\hline pWN3094 & $\begin{array}{l}\text { pBR322 with 4.2-kb Sau3A fragment harboring the E. chrysanthemi } \\
\text { hns gene }\end{array}$ & This work \\
\hline pWN3095 & $\begin{array}{l}\text { pBR322 with 2.4-kb ClaI-SphI fragment harboring the E. chrysan- } \\
\text { themi hns gene }\end{array}$ & This work \\
\hline pWN3096 & $\begin{array}{l}\text { pBR322 with } 1.1-\mathrm{kb} \text { ClaI-HindIII fragment harboring the E. chrysan- } \\
\text { themi hns gene }\end{array}$ & This work \\
\hline pRK767 & Mobilizable vector, $\mathrm{Tc}^{\mathrm{r}}$, $\mathrm{RK} 2$ derivative & Gill and Warren 1988 \\
\hline pWN3097 & $\begin{array}{l}\text { pRK } 767 \text { derivative with } 1.1-\mathrm{kb} \text { ClaI-HindIII fragment harboring the } E \text {. } \\
\text { chrysanthemi hns gene }\end{array}$ & This work \\
\hline pSR2489 & $\begin{array}{l}\text { pUC18 with an } 8.8-\mathrm{kb} \text { Sau } 3 \mathrm{~A} \text { fragment harboring the E. chrysanthemi } \\
\text { proU operon }\end{array}$ & This work \\
\hline \multicolumn{3}{|c|}{ 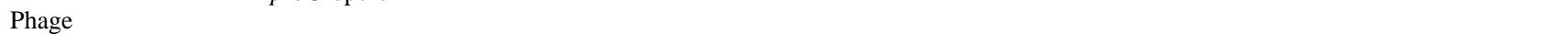 } \\
\hline PhiEC2 & General transducing phage of $E$. chrysanthemi & Résibois et al. 1984 \\
\hline
\end{tabular}

\footnotetext{
${ }^{a}$ Genotype symbols are according to Bachmann (1990). $\operatorname{lm} r T^{c}=$ transport system encoded by the gene $\operatorname{lm} r T$, which mediates entry of lactose, melibiose,
} and raffinose into the cells, is constitutively expressed. lac $Z$ indicates that the $3^{\prime}$ end of this gene is truncated. 
was obtained after growth in a low-phosphate-concentration medium as described (Roeder and Collmer 1985). The hns::Kan ${ }^{\mathrm{r}}$ marker exchange was performed in a merodiploid strain harboring the native $h n s$ gene on a low-copy number plasmid pRK767. After successful integration of the hns::Kan ${ }^{\mathrm{r}}$ construction into the chromosome, the pRK-hns plasmid was eliminated by successive cultures without antibiotic.

The uidA-Cm cassette (Bardonnet and Blanco 1992) includes a promoterless uidA gene with a conserved ShineDalgarno sequence. Insertion of this cassette in a gene in the correct orientation generates a transcriptional fusion.

Plasmid pSR2489 containing the proU operon was linearized with MamI, which is located in the coding ProV region, and ligated with the $3.8-\mathrm{kb}$ uidA-Cm cassette obtained by SmaI digestion of pUIDC1. Ampicillin- and chloramphenicolresistant clones were selected and checked for their production of $\beta$-glucuronidase. Restriction analysis of the plasmids confirmed the correct localization and orientation of the uidA-Cm cassette. One plasmid giving rise to a proV::uidA fusion was then introduced into E. chrysanthemi. Marker exchange recombination between the chromosomal allele and the plasmidborne mutated allele was selected after successive culture in low-phosphate medium in the presence of chloramphenicol. The A3779 strain containing the proV::uidA fusion was retained to study ProV regulation.

\section{Plate tests and enzyme assays.}

Clones producing pectate lyases were detected on medium containing polygalacturonate. After growth, plates were flooded with a solution of copper acetate $(10 \%)$, which forms a blue complex with the polymer, leaving clear haloes around clones producing pectate lyases. Detection of cellulase activity was performed with Congo red as described (Teather and Wood 1982). Assays of pectate lyases, $\beta$-glucuronidase, and $\beta$-galactosidase were performed on toluenized cell extracts. Pectate lyase activity was assayed as described (Moran et al. 1968). $\beta$-Glucuronidase activity was measured by following the degradation of $p$-nitrophenyl- $\beta$-D-glucuronide as described (Bardonnet and Blanco 1992). $\beta$-Galactosidase activity was measured by following the degradation of $o$-nitrophenyl- $\beta$-Dgalactoside as described (Miller 1972).

\section{Recombinant DNA and RNA techniques.}

Preparations of E. chrysanthemi chromosomal DNA, plasmid DNA, restriction digestions, ligations, DNA electrophoresis, transformations, and electroporations were carried out as described by Ausubel et al. (1987). Nucleotide sequence analysis was performed by the chain-termination method with a double-stranded DNA template and the use of a T7 sequencing kit (Pharmacia, Uppsala, Sweden). The resulting data were analyzed by the MAC Molly TETRA program (SoftGene, Berlin, Germany). The generation of the E. chrysanthemi gene library was performed as described (Reverchon et al. 1997).

The procedure for RNA isolation has been described previously (Reverchon et al. 1997). The concentration of RNA in different samples was detected spectrophotometrically, normalized for each sample, and verified on a reference gel with rRNA as the loading control. For Northern blot analysis, total RNAs were separated on formamide-formaldehyde denaturing 1\% agarose gels (Ausubel et al. 1997). The 1,185-bp
MamI-Bst1107I fragment from pSR1662 was used as the celZ probe and the 800-bp PstI-XhoI of pWN2144 was used as the $k d g R$ probe.

\section{Analytical procedures.}

Isoelectrofocusing was performed with a polyacrylamide gel containing a pharmalyte gradient (Pharmacia) from $\mathrm{pH} 3$ to $\mathrm{pH} 10$. An overlay with a PGA-CaCl2-agarose gel and staining with $0.05 \%$ ruthenium red allowed for the specific detection of pectate lyase activity.

\section{Pathogenicity tests.}

Chicory leaf infections were performed as described by Reverchon et al. (1997). Five leaves were inoculated with each strain and incubated at $30^{\circ} \mathrm{C}$ in a dew chamber at $100 \%$ relative humidity. Disease severity was determined 2 days after inoculation. To determine bacterial multiplication, rotted tissue were collected and homogenized in M63 medium. Colony forming units were determined by plating appropriate dilutions on agar plates. Pathogenicity on 24 potted S. ionantha plants was assayed as described by Sauvage and Expert (1994) with minor modifications; overnight bacterial cultures grown in M63 medium containing glycerol as the carbon source were diluted to reach an optical density at $600 \mathrm{~nm}$ of 0.3 . The inoculum was contained in $100 \mu \mathrm{l}$ of the resulting suspension (approximately $3 \times 10^{7}$ bacteria). Progression of proV symptoms was scored daily for 6 days.

\section{ACKNOWLEDGMENTS}

We thank A. Buchet, G. Condemine, and T. Franza for their critical opinions, and V. James for reading the manuscript. Appreciation is expressed to J. Robert-Baudouy for her support, and P. Lejeune for providing the E. coli strains TP500 and TP504 and for suggestions on the strategy of E. chrysanthemi hns cloning. This work was supported by grants from the Centre National de la Recherche Scientifique and the Ministère de l'Education Nationale, de l'Enseignement Supérieur, de la Recherche et de l'Insertion Professionnelle.

\section{LITERATURE CITED}

Atlung, T., and Ingmer, H. 1997. H-NS: A modulator of environmentally regulated gene expression. Mol. Microbiol. 2:7-17.

Ausubel, F. M., Brent, R., Kingston, R. E., Moore, D. D., Seidman, J. G., Smith, J. A., and Struhl, K. 1987. Current Protocols in Molecular biology. Wiley Interscience, New York.

Bachmann, B. S. 1990. Linkage map of Escherichia coli K12. Edition 8. Microbiol. Rev. 54:130-197.

Bardonnet, N., and Blanco, C. 1992. uidA antibiotic resistance cassettes for insertion mutagenesis, gene fusion and genetic constructions. FEMS Microbiol. Lett. 93:243-248.

Barras, F., El Hassouni, M., Chambost, J. P., and Chippaux, M. 1989. The beta-glucosides metabolism in Erwinia chrysanthemi: Preliminary analysis and comparison to Escherichia coli systems. FEMS Microbiol. Rev. 5:143-147.

Barron, A., May, G., Bremer, E., and Villarejo, M. 1986. Regulation of envelope protein composition during adaptation to osmotic stress in Escherichia coli. J. Bacteriol. 167:433-438.

Bauer, D. W., Bogdanove, A. J., Beer, S. V., and Collmer, A. 1994. Erwinia chrysanthemi hrp genes and their involvement in soft rot pathogenesis and elicitation of the hypersensitive response. Mol. PlantMicrobe Interact. 7:573-581.

Bertin, P., Benhabilles, N., Krin, E., Laurent-Winter, C., Tendeng, C., Turlin, E., Thomas, A., Danchin, A., and Brasseur, R. 1999. The structural and functional organization of H-NS-like proteins is evolutionarily conserved in Gram-negative bacteria. Mol. Microbiol. 31:319-329. 
Bourson, C., Favey, S., Reverchon, S., and Robert-Baudouy, J. 1993. Regulation of the expression of a pelA::uidA fusion in Erwinia chrysanthemi and demonstration of the synergistic action of plant extract with polygalacturonate on pectate lyase synthesis. J. Gen. Microbiol. 139:1-9.

Castillo, A., and Reverchon, S. 1997. Characterization of the pecT control region from Erwinia chrysanthemi strain 3937. J. Bacteriol. 179:4909-4918.

Collmer, A., and Keen, N. T. 1986. The role of pectic enzymes in plant pathogenesis. Annu. Rev. Phytopathol. 24:383-409.

Colonna, B., Casalino, M., Fradiani, P. A., Zagaglia, C., Naitza, S., Leoni, L., Prosseda, G., Coppo, A., Ghelardini, P., and Nicoletti, M. 1995. H-NS regulation of virulence gene expression in enteroinvasive Escherichia coli harboring the virulence plasmid integrated into the host chromosome. J. Bacteriol. 177:4703-4712.

Condemine, G., Castillo, A., Passeri, F., and Enard, C. 1999. The PecT repressor coregulates synthesis of exopolysaccharides and virulence factors in Erwinia chrysanthemi. Mol. Plant-Microbe Interact. 12:4552.

Dattananda, C. S., and Gowrishankar, J. 1989. Osmoregulation in Escherichia coli: Complementation analysis and gene-protein relationships in the proU locus. J. Bacteriol. 171:1915-1922.

Defez, R., and De Felice, M. 1981. Cryptic operon for $\beta$ glucoside metabolism in E. coli $\mathrm{K} 12$ : Genetic evidence for a regulatory protein. Genetics 97:11-25

Dorman, J. C., Hinton, J. C. D., and Free, A. 1999. Domain organization and oligomerization among H-NS-like nucleoid-associated proteins in bacteria. Trends Microbiol. 7:124-128.

El Hassouni, M. E., Chambost, J. P., Expert, D., Van Gijsegem, F., and Barras, F. 1999. The minimal gene set member $m s r A$, encoding peptide methionine sulfoxide reductase, is a virulence determinant of the plant pathogen Erwinia chrysanthemi. Proc. Natl. Acad. Sci. USA 96:887-892.

Enard, C., Diolez, A., and Expert, D. 1988. Systemic virulence of Erwinia chrysanthemi 3937 requires a functional iron assimilation system. J. Bacteriol. 170:2419-2426.

Falconi, M., Higgins, N. P., Spurio, R., Pon, C. L., and Gualerzi, C. O. 1993. Expression of the gene encoding the major bacterial nucleoid protein H-NS is subject to transcriptional autorepression. Mol. Microbiol. 10:273-262.

Fleischmann, R. D., Adams, M. D., White, O., Clayton, R. A., Kirkness, E. F., Kerlavage, A. R. 1995. Whole-genome random sequencing and assembly of Haemophilus influenzae Rd. Science 269:496-512.

Franza, T., Sauvage, C., and Expert, D. 1999. Iron regulation and pathogenicity in Erwinia chrysanthemi 3937: Role of the Fur repressor protein. Mol. Plant-Microbe Interact. 12:119-128.

Gill, P. R., and Warren, G. J. 1988. An iron-antagonized fungistatic that is not required for iron assimilation from a fluorescent rhizosphere pseudomonad. J. Bacteriol. 170:163-170.

Gouesbet, G., Trautwetter, A., Bonnassie, S., Wu, L. F., and Blanco, C. 1996. Characterization of the Erwinia chrysanthemi osmoprotectant transport gene ousA. J. Bacteriol. 178:447-455.

Gottesman, S. 1995. Regulation of capsule synthesis: Modification of a two component paradigm by an accessory unstable protein. Pages 253-262 in: Two-Component Signal Transduction. J. A. Hoch and T. J. Silhavy, eds. American Society for Microbiology, Washington, DC.

Goyard, S., and Bertin, P. 1997. Characterisation of BpH3, an H-NS like protein in Bordetella pertussis. Mol. Microbiol. 24:815-823.

Harrison, J. A., Pickard, D., Higgins, C. F., Khan, A., Chatfield, S. N., Ali, T., Dorman, J. C., Hormaeche, C. E., and Dougan, G. 1994. Role of $h n s$ in the virulence phenotype of pathogenic salmonellae. Mol. Microbiol. 13:133-140.

Higgins, C. F., Dorman, C. J., Stirling, D. A., Waddell, L., Booth, I. R., May, G., and Bremer, E. 1988. A physiological role for DNA supercoiling in the osmotic regulation of gene expression in S. typhimurium and E. coli. Cell 52:569-584.

Hinton, J. C. D., Santos, D. S., Seirafi, A., Hulton, C. S. J., Pavitt, G. D., and Higgins, C. F. 1992. Expression and mutational analysis of the nucleoid-associated protein H-NS of Salmonella typhimurium. Mol. Microbiol. 6:2327-2337.

Hugouvieux-Cotte-Pattat, N., Condemine, G., Nasser, W., and Reverchon, S. 1996. Regulation of pectinolysis in Erwinia chrysanthemi. Annu. Rev. Microbiol. 50:213-257.

Hugouvieux-Cotte-Pattat, N., and Robert-Baudouy, J. 1985. Lactose catabolism in Erwinia chrysanthemi. J. Bacteriol. 162:248-255

Hulton, C. S. J., Seirafi, A., Hinton, J. C. D., Sidebotham, J. M. Waddell, L., Pavitt, G. D., Owen-Hughes, T., Spassky, A., Buc, H., and Higgins, C. F. 1990. Histone-like protein H1 (H-NS), DNA supercoiling, and gene expression in bacteria. Cell 63:631-642.

James, V., and Hugouvieux-Cotte-Pattat, N. 1996. Regulatory systems modulating the transcription of the pectinase genes of Erwinia chrysanthemi are conserved in Escherichia coli. Microbiology 142:26132619.

La Teana, A., Brandi, A., Falconi, M., Spurio, R., Pon, C. L., and Gualerzi, C. O. 1991. Identification of a cold shock transcriptional enhancer of the Escherichia coli gene encoding nucleoid protein $\mathrm{H}-$ NS. Proc. Natl. Acad. Sci. USA 88:10907-10911.

Lejeune, P., and Danchin, A. 1990. Mutations in bglY gene increase the frequency of spontaneous deletions in Escherichia coli K-12. Proc. Natl. Acad. Sci. USA 87:360-363.

Lopez-Solanilla, E., Garcia-Olmedo, F., and Rodriguez-Palenzuela, P. 1998. Inactivation of the sapA to sapF locus of Erwinia chrysanthem reveals common features in plant and bacterial pathogenesis. Plant Cell 10:917-924.

Lucht, J. M., Dersch, P., Kempf, B., and Bremer, E. 1994. Interactions of the nucleoid-associated DNA-binding protein H-NS with the regulatory region of the osmotically controlled proU operon of Escherichia coli. J. Biol. Chem. 269:6578-6586.

Maurelli, A. T., and Sansonetti, P. J. 1988. Identification of a chromosomal gene controlling temperature-regulated expression of Shigella virulence. Proc. Natl. Acad. Sci. USA 85:2820-2824.

Miller, J. H. 1972. Experiment in Molecular Genetics. Cold Spring Harbor Laboratory, Cold Spring Harbor, NY, U.S.A.

Moran, F., Nasuno, S., and Starr, M. P. 1968. Extracellular and intracellular polygalacturonic acid trans eliminase of Erwinia carotovora. Arch. Biochem. Biophys. 123:293-306.

Mukherjee, A., Cui, Y., Ma, W., Liu, Y., Ishihama, A., Eisenstark, A. and Chatterjee, A. 1998. RpoS (Sigma-S) controls expression of $r m s A$, a global regulator of secondary metabolites, harpin, and extracellular proteins in Erwinia carotovora. J. Bacteriol. 180:3629-3634.

Mulholland, V., Hinton, J. C. D., Sidebotham, J., Toth, I. K., Hyman, L. J., Perombelon, M. C. M., Reeves, P. J., and Salmond, G. P. C. 1994 A pleiotropic reduced virulence (Rvi-) mutant of Erwinia carotovora subspecies atroseptica is defective in flagella assembly proteins that are conserved in plant and animal bacterial pathogens. Mol. Microbiol. 9:343-356.

Nasser, W., Reverchon, S., Condemine, G., and Robert-Baudouy, J. 1994. Specific interactions of Erwinia chrysanthemi KdgR repressor with different operators of genes involved in pectinolysis. J. Mol. Biol. 236:427-440.

Nasser, W., Robert-Baudouy, J., and Reverchon, S. 1997. Antagonistic effect of CRP and $\mathrm{KdgR}$ in the transcription control of the Erwinia chrysanthemi pectinolysis genes. Mol. Microbiol. 26:1071-1082.

Nasser, W., Bouillant, M. L., Salmond, G. P. C., and Reverchon, S 1998. Characterization of the Erwinia chrysanthemi expI-expR locus directing the synthesis of two $\mathrm{N}$-acyl-homoserine lactone signal molecules. Mol. Microbiol. 29:1391-1405.

Nomura, K., Nasser, W., Kawagishi, H., and Tsuyumu, S. 1998. The pir gene of Erwinia chrysanthemi EC16 regulates hyperinduction of pectate lyase virulence genes in response to plant signals. Proc. Natl. Acad. Sci. USA 95:14034-14039.

Praillet, T., Nasser, W., Robert-Baudouy, J., and Reverchon, S. 1996 Purification and functional characterization of PecS: A regulator of virulence factor synthesis in Erwinia chrysanthemi. Mol. Microbiol. 20:391-402

Résibois, A., Colet, M., Faelen, M., Schoonejans, E., and Toussaint, A. 1984. Phi-EC2 a new generalized transducing phage of Erwinia chrysanthemi. Virology 137:102-112.

Reverchon, S., Expert, D., Robert-Baudouy, J., and Nasser, W. 1997. The cyclic AMP receptor protein is the main activator of the pectinolysis genes in Erwinia chrysanthemi. J. Bacteriol. 179:3500-3508.

Reverchon, S., Nasser, W., and Robert-Baudouy, J. 1991. Characterization of $k d g R$, a gene of Erwinia chrysanthemi that regulates pectin degradation. Mol. Microbiol. 5: 2203-2216.

Reverchon, S., Nasser, W., and Robert-Baudouy, J. 1994. pecS: A locus controlling pectinase, cellulase and blue pigment production in $\mathrm{Er}$ winia chrysanthemi. Mol. Microbiol. 11:1127-1139.

Reverchon, S., Bouillant, M. L., Salmond, G., and Nasser, W. 1998 
Integration of the quorum sensing system in the regulatory networks controlling virulence factor synthesis in Erwinia chrysanthemi. Mol. Microbiol. 29:1407-1418.

Roeder, D. L., and Collmer, A. 1985. Marker-exchange mutagenesis of a pectate lyase isoforme gene in Erwinia chrysanthemi. J. Bacteriol. 164:51-56.

Sauvage, C., and Expert, D. 1994. Differential regulation by iron of Erwinia chrysanthemi pectate lyases: Pathogenicity of iron transport regulatory $(c b r)$ mutants. Mol. Plant-Microbe Interact. 7:71-77.

Schoonejans, E., Expert, D., and Toussaint, A. 1987. Characterisation and virulence properties of Erwinia chrysanthemi lipopolysaccharidedefective, phiEC2-resistant mutants. J. Bacteriol. 169:4011-4017.

Sledjeski, D., and Gottesman, S. 1995. A small RNA acts as an antisilencer of the H-NS-silence rcsA gene of Escherichia coli. Proc. Natl. Acad. Sci. USA 92:2003-2007.

Surgey, N., Robert-Baudouy, J., and Condemine, G. 1996. The Erwinia chrysanthemi pecT gene regulates pectinase gene expression. J. Bacteriol. 178:1593-1599.

Teather, R. M., and Wood, P. J. 1982. Use of Congo red polysaccharide interactions in enumeration and characterization of cellulolytic bacteria from bovine rumen. Appl. Environ. Microbiol. 43:777-780.

Ueguchi, C., Kakeda, M., and Mizuno, T. 1993. Autoregulatory expression of the Escherichia coli hns gene encoding a nucleoid protein: $\mathrm{H}-$ NS functions as a repressor of its own transcription. Mol. Gen. Genet. 236:171-178

Ussery, D. W., Hinton, J. C. D., Jordi, B. J. A. M., Granum, P. E., Seirafi, A., Stephen, R. J., Tupper, A. E., Berridge, G., Sidebotham, J. M., and Higgins, C. F. 1994. The chromatin-associated protein H-NS. Biochimie 76:968-980.

Zhang, A., and Belfort, M. 1992. Nucleotide sequence of a newlyidentified Escherichia coli gene, stpA, encoding an H-NS-like protein. Nucleic Acids Res. 20:6735. 